\title{
Vascularisation of the geniculate ganglion
}

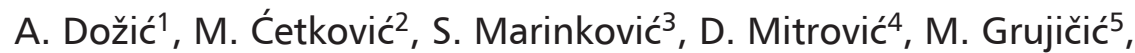 \\ M. Mićović6, M. Milisavljević 1 \\ ${ }^{1}$ Department of Anatomy, Institute of Anatomy, Faculty of Dentistry, University of Belgrade, Belgrade, Serbia \\ ${ }^{2}$ Department of Histology and Embryology, Institute of Histology and Embryology, Faculty of Medicine, \\ University of Belgrade, Belgrade, Serbia \\ ${ }^{3}$ Department of Neuroanatomy and Gross Anatomy, Institute of Anatomy, Faculty of Medicine, University of Belgrade, \\ Belgrade, Serbia \\ ${ }^{4}$ Department of Pathology, Institute of Pathology, Faculty of Medicine, University of Belgrade, Belgrade, Serbia \\ ${ }^{5}$ Emergency Centre, General Hospital, Smederevo, Serbia

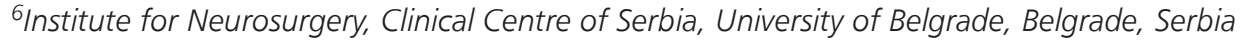 \\ ${ }^{7}$ Department of Anatomy, Institute of Anatomy, Faculty of Medicine, University of Belgrade, Belgrade, Serbia
}

[Received 12 May 2014; Accepted 9 June 2014]

Background: Lack of the relevant data in the literature and possible clinical significance of the geniculate ganglion vasculature inspired us to examine the vessels of this ganglion.

Materials and methods: Twelve temporal bones were taken during autopsy and microdissected. Four geniculate ganglions were taken as well, serially sectioned and used for haematoxylin-eosin and trichrome staining, and for CD34 immunostaining. Results: The geniculate ganglion was supplied by the petrosal artery, which averaged 1.1 in number, $0.44 \mathrm{~mm}$ in the outer diameter, $0.24 \mathrm{~mm}$ in the luminal diameter, and $17.1 \mathrm{~mm}$ in length. The artery approached the greater petrosal nerve, giving off 1-3 twigs to it with a mean diameter of $24 \mu \mathrm{m}$, and entered the nerve hiatus or a small bone opening close to the ganglion. Before the artery continued to the tympanic segment of the facial nerve, it gave rise to 1 (8.33\%), $2(75.00 \%)$ or $3(16.67 \%)$ branches to the geniculate ganglion, which ranged in diameter between $18 \mu \mathrm{m}$ and $56 \mu \mathrm{m}$ (mean $29 \mu \mathrm{m}$ ). From the formed superficial network, several twigs penetrated the ganglion and built an intraganglionic plexus. The counting, performed in microscopic fields, each measuring $341.7 \mu \mathrm{m} \times 250.0 \mu \mathrm{m}$ in size, contained between 20 and 38 (mean 28.1) ganglion cells, as well as from 87 to 143 microvessels (mean 99.8), so that the neuron/vessel ratio was 1:3.6.

Conclusions: This is the first detailed examination of the geniculate ganglion vasculature. The obtained data could be of clinical importance, especially in relation to the Bell's palsy, ganglionitis, geniculate neuralgia, petrous bone imaging, and operations in the same region. (Folia Morphol 2014; 73, 4: 414-421)

Key words: anatomy, facial nerve, geniculate ganglion, immunohistochemistry, middle cranial fossa, vasculature

\section{INTRODUCTION}

The geniculate ganglion is a small collection of the somatosensory and gustatory ganglion cells located just in front of the genu of the facial nerve (see later
Fig. 6). The blood supply of the labyrinthine, tympanic and mastoid segments of the facial nerve was often examined, mainly in relation to the Bell's palsy and surgery in the region of the petrous bone and the adjacent

Address for correspondence: Prof. S. Marinković, MD, PhD, Department of Neuroanatomy and Gross Anatomy, Institute of Anatomy, Faculty of Medicine, Dr. Subotić 4/2, 11000 Belgrade, Serbia, tel: +381 11 2645958, fax: +381 11 2686172, e-mail: mocamarinkovic@med.bg.ac.rs 
areas $[2-7,11,12,14,18]$. However, the researchers rarely focused their attention on the vascularisation of the geniculate ganglion itself $[2,3,5,11]$.

Since the knowledge about the ganglion vasculature can be important in relation to the haemangioma, Bell's palsy, ganglionitis, geniculate neuralgia and, especially, to the microsurgical interventions in the petrous and surroundings regions $[3,6,10$, $12,19]$, we decided to examine the source of the ganglion supply, the microanatomical features of the efferent ganglionic vessels, and the intraganglionic vascular network.

\section{MATERIALS AND METHODS}

The examination was carried out in 16 temporal bones, i.e. in 14 taken from adults ( 9 males and 5 females aged 36-69 years, mean 52.1) and in 2 from foetuses of 7 months.

The temporal bones were taken during routine autopsy after providing approval from authorities of the Institute of Pathology and the Ethical Committee of the Clinical Centre, University of Belgrade. None of the autopsied persons had any disease of the skull and brain. The bones with the soft tissues of the underlying infratemporal fossa were cut off using a fine electric saw. A catheter was inserted into the lower part of the middle meningeal artery (MMA), which was injected with a $10 \%$ hot mixture of India ink and gelatine. Each injected specimen was then immersed in a $10 \%$ formaldehyde solution and fixed for 3 weeks.

Subsequently, the dura mater of the temporal bone was partially removed. In spite of a very careful microdissection, 4 specimens were damaged during the procedure and excluded from the examination. The petrosal artery and the greater petrosal nerve in the remaining 12 specimens were carefully dissected under the stereoscopic microscope (Leica MZ6) using neurosurgical microinstruments. Photographs were taken by a digital photo camera (Canon Power Shot A710). The statistical analysis comprised the mean values of the obtained data.

In addition, 4 geniculate ganglions of adult persons were taken during autopsy after removing a thin part of the tegmen tympani with the dura mater. Each ganglion was immersed in isotonic saline solution, fixed in $4 \%$ buffered formaldehyde, dehydrated, embedded in paraffin and sectioned serially in $5 \mu \mathrm{m}$ thick slides. Every tenth slice was stained with haematoxylin and eosin, and every $11^{\text {th }}$ one with the
Masson trichrome method in a standard manner [9]. Every $12^{\text {th }}$ and $13^{\text {th }}$ slice was prepared for immunohistochemistry [9]. There were 8 such slices altogether.

The latter slices underwent the immunostaining using the mouse monoclonal primary serum against CD34 (DAKO A/S, Denmark M 7168). All slices were treated for antigen retrieval prior to staining. The slices were stained for the mentioned antigen by the streptavidin-biotin peroxidase complex method (Universal LSAB+Kit HPR; DAKO ${ }^{\circledR}$ Cytomation K0679, Glostrup, Denmark) using as chromogens 3-amino-9-ethylcarbazole (AEC, No. K3469, DAKO ${ }^{\circledR}$ ). The sections were counterstained with Mayer's haematoxylin. The intensity of staining was evaluated semiquantitatively by 2 independent investigators. The intensity of all the slices but one was classified as strongly positive. Positive and negative tissues were included as controls in order to determine the specificity of immunostaining.

The slices were examined under the light microscope (Leica DMLS) and photographed by a digital photocamera (Leica DFC295). Measurements were performed using a special software (Leica Interactive Measurements). Statistical analysis comprised mean values, as well as standard deviation (SD), standard error (SE), and a confidence interval in some cases.

\section{RESULTS}

We examined the portion of the middle cranial fossa, i.e. of the anterior (superior) surface of the petrous part of the temporal bone (Fig. 1). This region contained anteriorly the MMA emerging from the foramen spinosum, then part of the internal carotid artery, the trigeminal ganglion with its 3 divisions, and the lesser and greater petrosal nerves. Posteriorly the geniculate ganglion was located, along with the labyrinthine and tympanic segments of the facial nerve, as well as the structures of the inner ear (Fig. 1). The petrosal artery was also noticed in the region of the petrous bone.

\section{Petrosal artery}

Our study revealed that the geniculate ganglion was supplied by the petrosal artery, which was present in all the cases (Fig. 2). The artery was singular in all the 12 (91.67\%) specimens, except in $1(8.33 \%)$ with an additional vessel from a trigeminal branch.

The petrosal artery always originated from the MMA, which was a constant and normally developed 


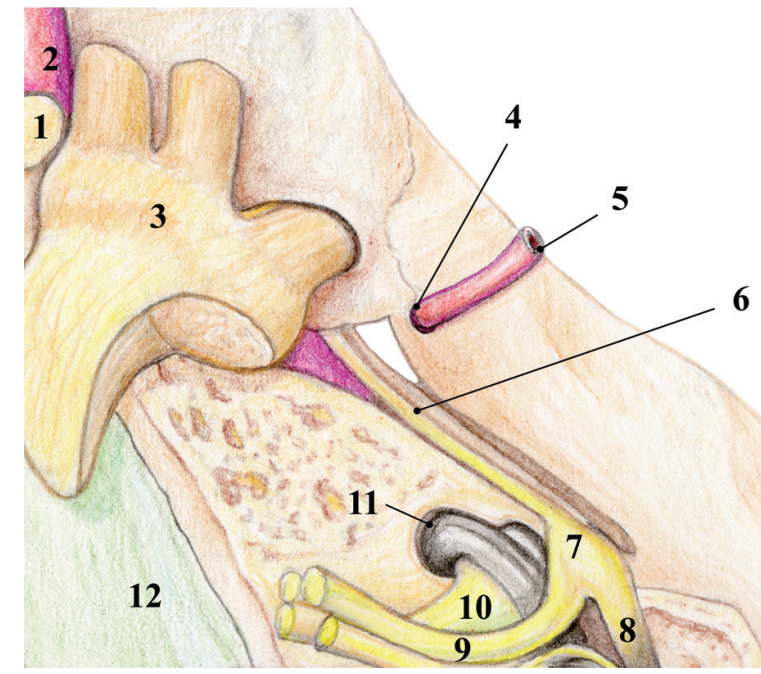

Figure 1. Drawing of the petrous part (partially cut) of the right temporal bone in a superior view; 1 - posterior clinoid process; 2 - cavernous segment of the internal carotid artery; 3 - trigeminal ganglion (partially cut); 4 - foramen spinosum; 5 - middle meningeal artery; 6 - greater petrosal nerve; 7 - geniculate ganglion; 8 - tympanic, 9 - labyrinthine segment of the facial nerve; 10 - cochlear nerve; 11 - cochlea; 12 - dura mater.

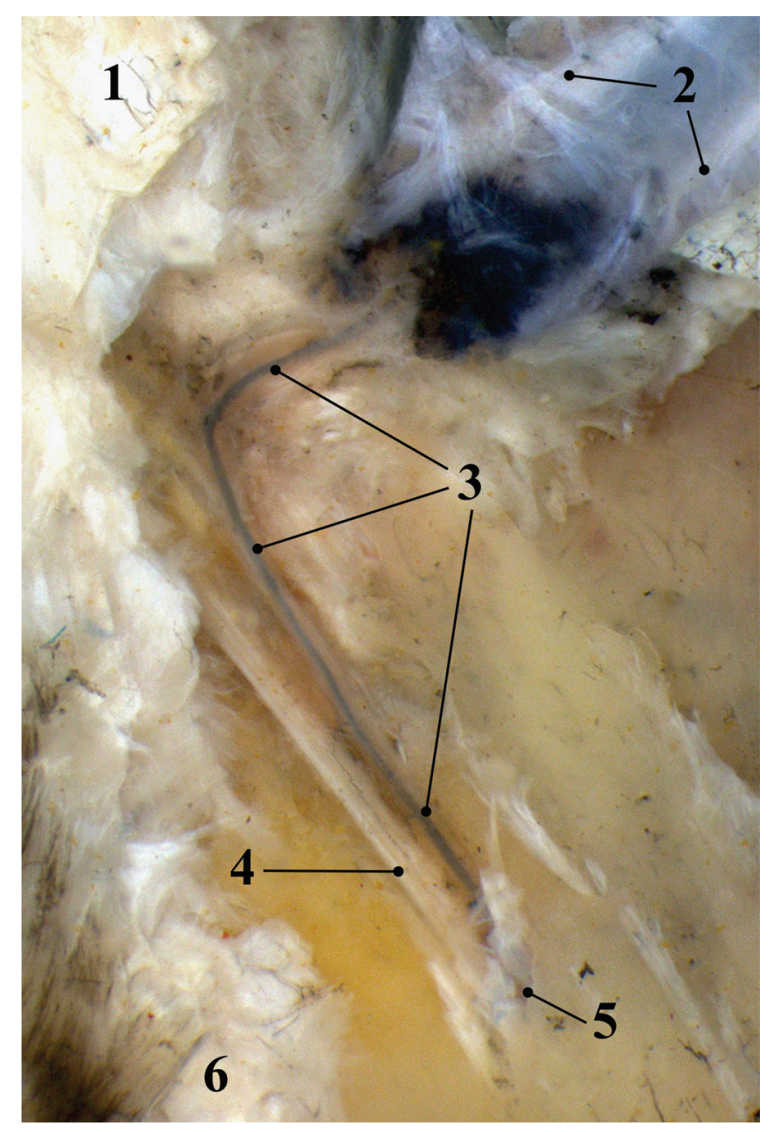

Figure 2. Superior view of the right petrous bone (compare to Fig. 1); 1 - trigeminal ganglion; 2 - middle meningeal artery; 3 - petrosal artery, which follows the greater petrosal nerve (4) to its hiatus (5); 6 - dura mater (partially removed). vessel passing through the foramen spinosum of the middle cranial fossa (Fig. 1). The outer diameter of the MMA ranged from $0.5 \mathrm{~mm}$ to $1.9 \mathrm{~mm}$, and averaged $1.3 \mathrm{~mm}$. The petrosal artery originated from the initial intracranial stem of the MMA, immediately above the foramen spinosum and just lateral to the lesser and greater petrosal nerves, as well as to the trigeminal ganglion (Fig. 2).

The petrosal artery is a small vessel, whose outer diameter averaged $0.44 \mathrm{~mm}$, and the inner (luminal) diameter only $0.24 \mathrm{~mm}$ (Table 1). After taking its origin from the MMA, the artery coursed posteriorly and slightly laterally, at an acute angle to the greater petrosal nerve (Fig. 3), whose diameter ranged between $0.20 \mathrm{~mm}$ and $0.44 \mathrm{~mm}$ (mean $0.31 \mathrm{~mm}$ ). The artery most often (83.3\%) approached the proximal part of the nerve, i.e. in front of its hiatus (Fig. 3). In these cases, the shortest distance from the initial part of the artery to the distal segment of the nerve averaged $3.6 \mathrm{~mm}$ (Table 1). The terminal part or larger portion of the artery was sometimes covered by a thin plate of the bone.

The petrosal artery in $2(16.7 \%)$ specimens approached the distal part of the petrosal segment of the nerve, i.e. close to the trigeminal ganglion (Fig. 2). In these cases, the artery ran along the nerve and entered its hiatus in the petrous bone. The petrosal artery averaged $17.1 \mathrm{~mm}$ in length (Table 1).

In a single specimen (8.33\%) with 2 petrosal arteries, one of them had a typical origin from the MMA, and it approached the proximal part of the nerve. The other one, however, arose from a trigeminal artery, which in turn originated from the MMA. The trigeminal artery ran along the posterolateral part of the trigeminal ganglion and, in addition to the trigeminal twigs, also gave rise to a recurrent petrosal branch which coursed along the greater petrosal nerve and gave off small twigs for its supply.

No matter whether the petrosal artery approached the proximal or distal segment of the greater petrosal nerve, it always gave off 1 to 3 branches (mean 1.6) for supplying the nerve (Fig. 3). Some of the branches followed the nerve toward its distal part, some others toward its proximal part (Fig. 3). Those twigs ranged in the outer diameter between $0.012 \mathrm{~mm}$ and $0.052 \mathrm{~mm}$ (mean $0.024 \mathrm{~mm}$, i.e. $24 \mu \mathrm{m}$ ).

\section{Ganglion vasculature}

The terminal part of the petrosal artery entered the hiatus of the greater petrosal nerve in $25.0 \%$ of the cases, in order to reach the geniculate ganglion 
Table 1. Morphometric study of the petrosal artery — range (mean)

\begin{tabular}{lcccc}
\hline Number & Outer diameter $[\mathrm{mm}]$ & Inner diameter $[\mathrm{mm}]$ & Length $[\mathrm{mm}]$ & Distance $[\mathrm{mm}]$ \\
\hline $1-2(1.1)$ & $0.29-0.56(0.44)$ & $0.11-0.52(0.24)$ & $12.4-25.9(17.1)$ & $2.6-4.4(3.6)$ \\
\hline
\end{tabular}

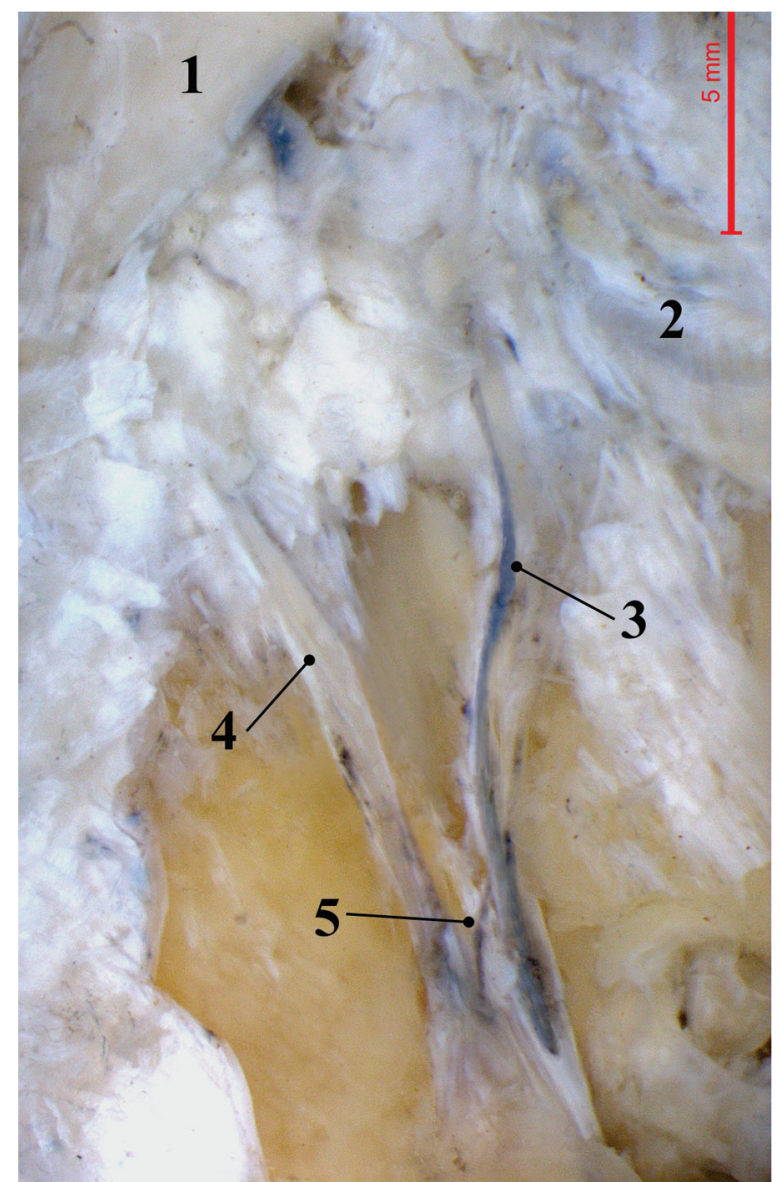

Figure 3. Superior view of the right petrous bone; 1 - trigeminal ganglion; 2 - middle meningeal artery; 3 - petrosal artery; 4 - greater petrosal nerve; 5 - a branch to the petrosal nerve.

and the tympanic segment of the facial nerve. In other specimens $(75.0 \%)$, however, it passed through a small bone opening located anterolateral to the ganglion. In any case, each petrosal artery coursed below or just lateral to the ganglion and continued then along the tympanic segment of the facial nerve.

When the petrosal artery was in a close proximity to the geniculate ganglion, it gave off $1(8.33 \%)$, $2(75.00 \%)$ (Fig. 4 ) or $3(16.67 \%)$ branches to the ganglion. These twigs ranged in the outer diameter from $0.018 \mathrm{~mm}$ to $0.056 \mathrm{~mm}$ (mean $0.029 \mathrm{~mm}$ ). The twigs ramified soon and formed a network on the surface of the ganglion (Figs. 4, 5), whose vessels entered the ganglion tissues.

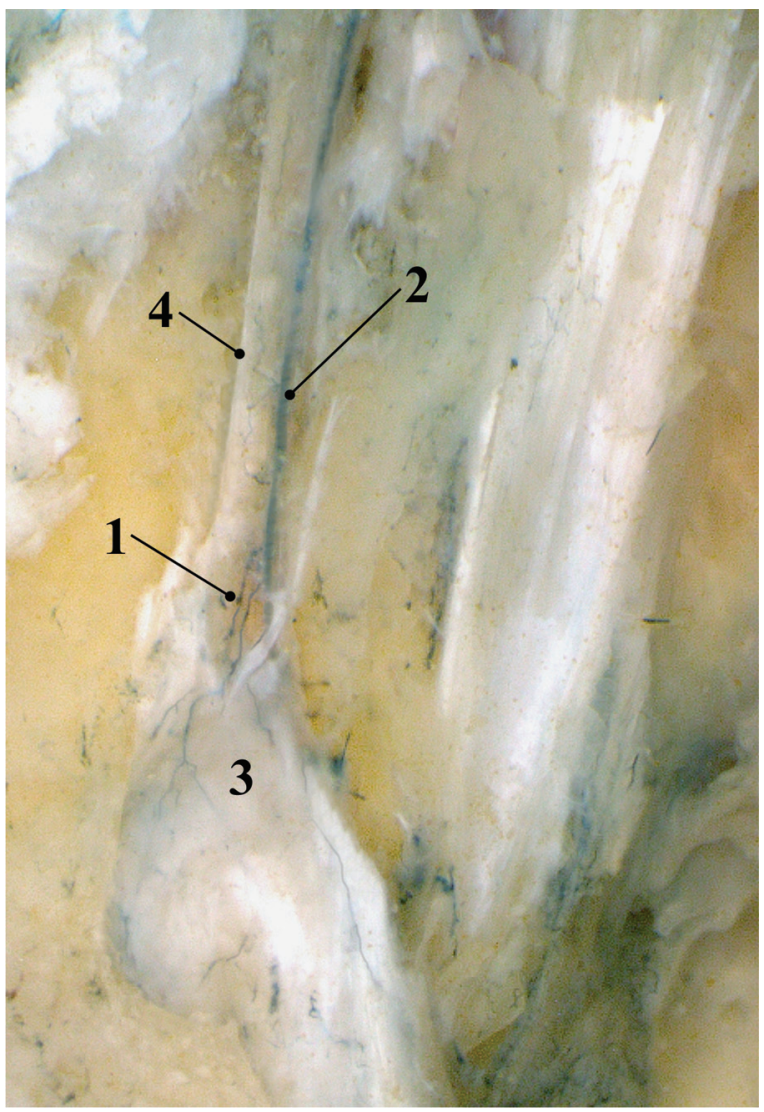

Figure 4. Superior view of the right petrous bone; $1-$ two branches of the petrosal artery (2) ramifying over the geniculate ganglion (3); 4 - greater petrosal nerve.

The microscopic examination of the intraganglionic vessels started following a trichrome staining of the histological slices (Figs. 6, 7). It was noticed that the larger and smaller individual vessels were filled with red cells. However, the immunohistochemical method, using an endothelial marker (CD34), revealed a rich network of the intraganglionic vessels (Figs. 8, 9).

The microvessels, mainly capillaries and precapillaries, coursed along and around the small groups of the ganglion neurons (Fig. 8), but the individual capillaries ran around each singular cell, which was especially evident at higher magnifications (Fig. 9). The vessels showed some sporadic local dilations. The number of the microvessels was counted in each single microscopic field of the 8 slices at $\times 400$ magnification. Each field, which measured $341.7 \mu \mathrm{m} \times 250.0 \mu \mathrm{m}$ in size, 


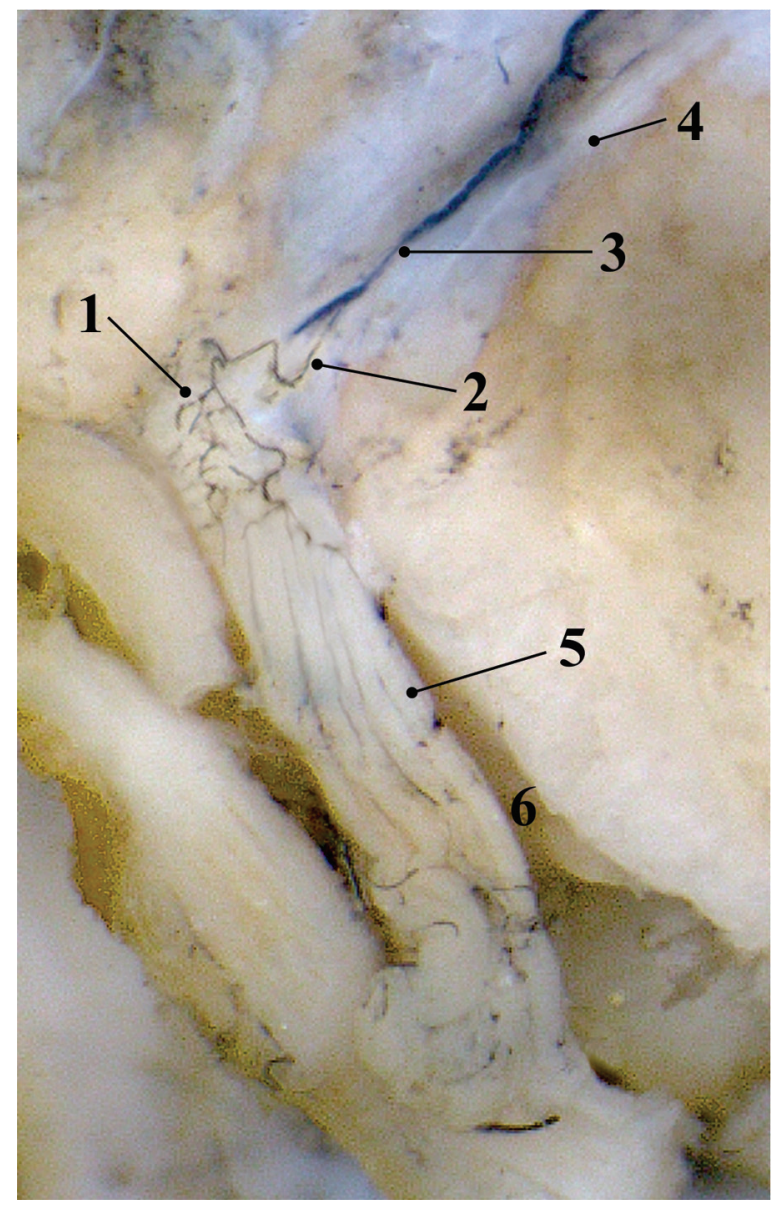

Figure 5. Superior view of the left petrous bone; 1 - superficial vascular network of a foetal geniculate ganglion formed by a branch (2) of the left petrosal artery (3); 4 - greater petrosal nerve; 5 - facial nerve; 6 - opened internal acoustic meatus.

contained from 87 to 143 microvessels (mean 99.8). The microvessels ranged in diameter from $5.47 \mu \mathrm{m}$ to $8.71 \mu \mathrm{m}$ (mean 6.84) and showed SD $= \pm 0.56, \mathrm{SE}=0.056$, and lower/upper confidence interval $=6.73 / 6.95$.

We also counted the number of the ganglion neurons in each field of the mentioned slices. Those cells ranged between 20 and 38 (mean 28.1) in number per field.

\section{DISCUSSION}

The facial nerve is typically divided into 3 topographical segments: the labyrinthine (within the initial part of the facial or Fallopian canal), the tympanic (along the border with the tympanic cavity) and the mastoid (along the border between the latter cavity and the mastoid process) $[2,3,8,17,18]$. The geniculate ganglion is located just anterior to the first genu of the nerve, i.e. between the labyrinthine and tympanic

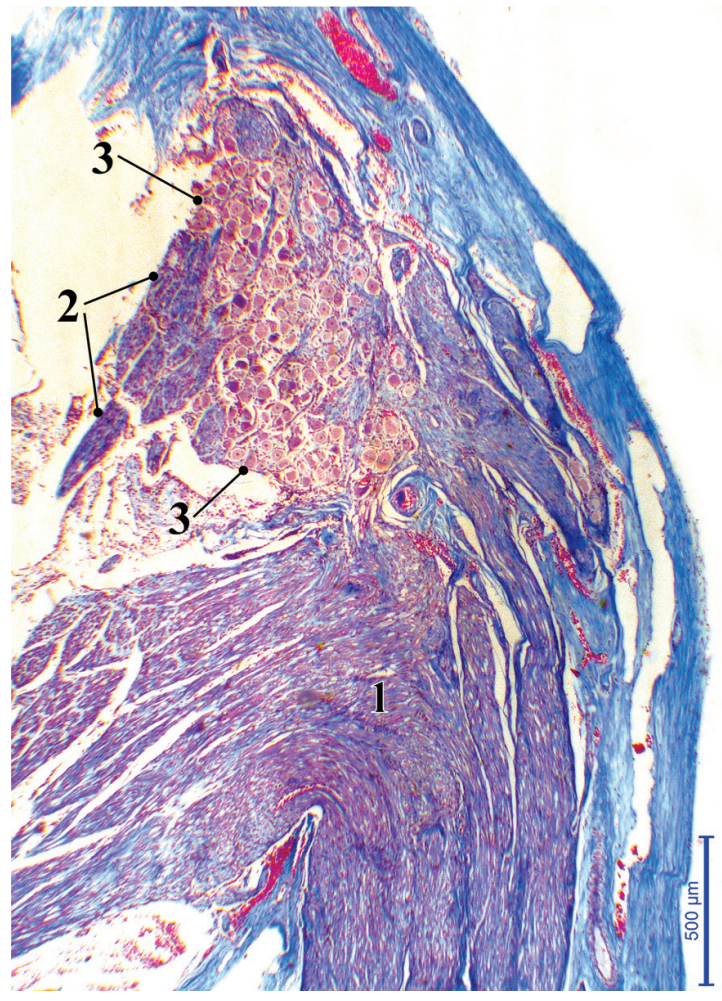

Figure 6. Microphotograph of the genu (1) of the facial nerve, the intermediate nerve (2), and the geniculate ganglion (3). Note the blood vessels with red cells (trichrome staining).

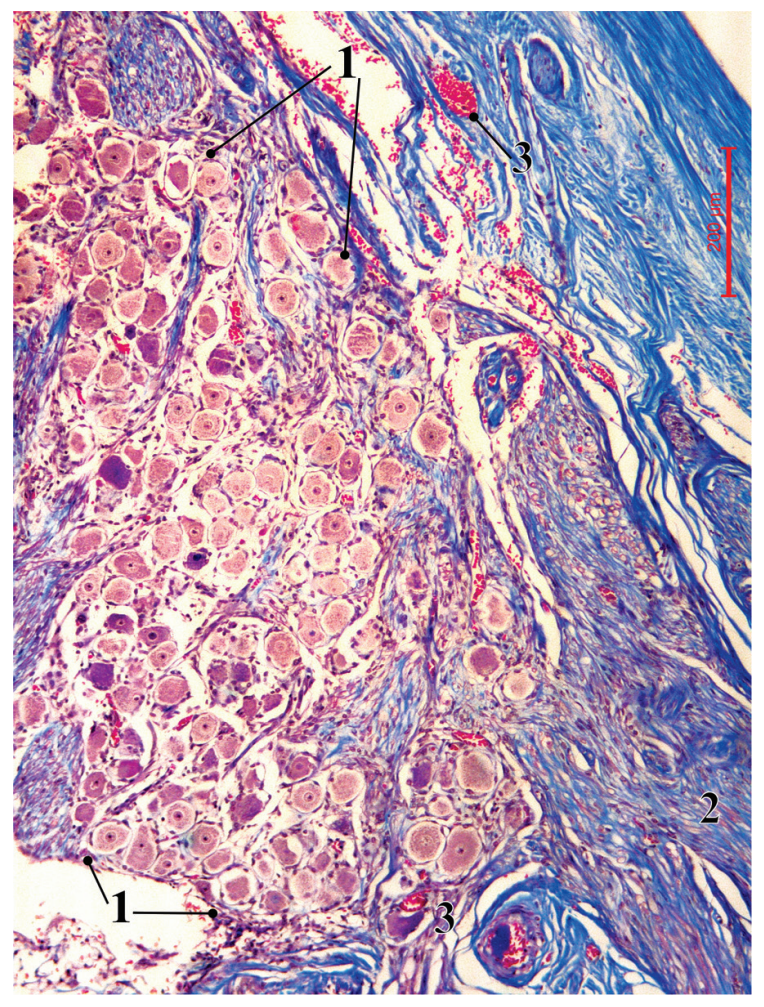

Figure 7. Larger magnification of the specimen in Figure $6 ; 1-$ geniculate ganglion with numerous ganglion neurons; 2 - facial nerve; 3 - larger blood vessels with red cells (trichrome staining). 


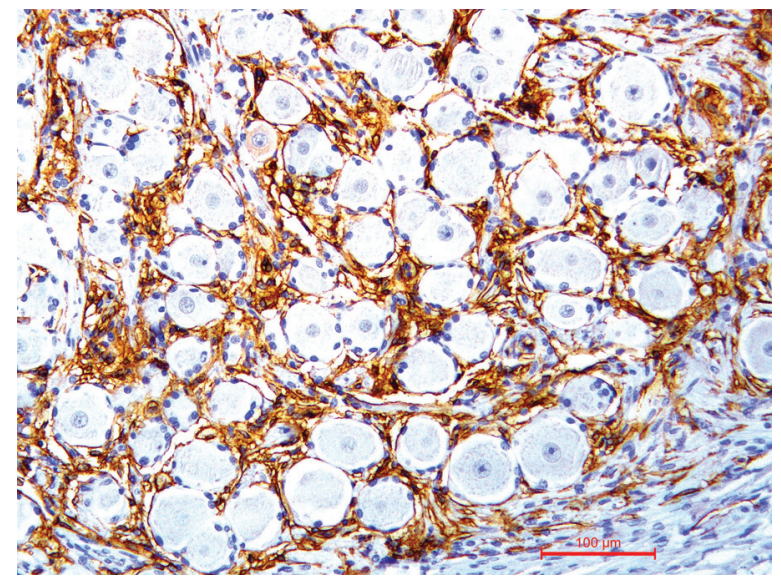

Figure 8. Microvasculature of the geniculate ganglion at lower magnification (CD34 immunostaining).

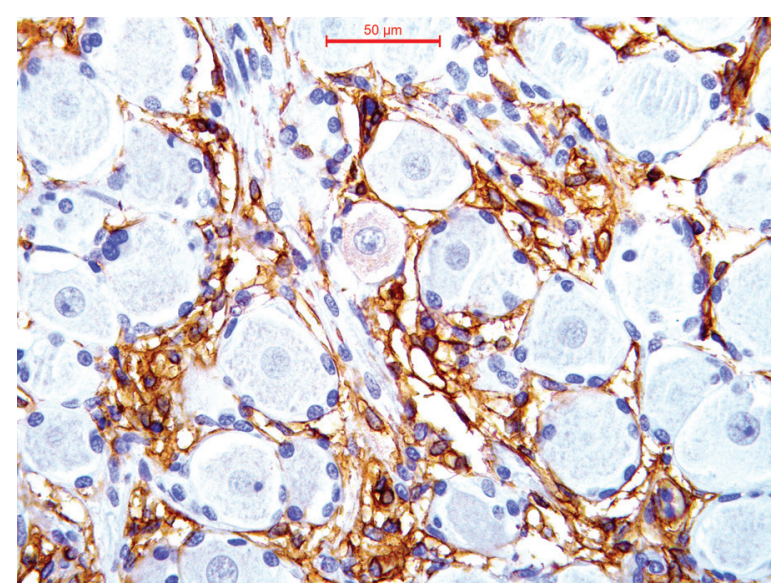

Figure 9. Microvasculature of the geniculate ganglion at higher magnification. Note numerous capillaries around the ganglion neurons and satellite cells (CD34 immunostaining).

segments of the facial nerve (Fig. 6). While the former segment is supplied by the labyrinthine (internal auditory) artery from the anterior inferior cerebellar artery, the mastoid segment is nourished by the stylomastoid vessel from the posterior auricular or occipital artery, and the tympanic segment is vascularised by the petrosal artery $[2,14,15,18]$. According to some authors, there are anastomoses between the stylomastoid and the petrosal arteries $[5,14,18]$.

As regards the geniculate ganglion, it is typically supplied by the petrosal artery $[12,14]$. In the course of our preliminary examination of the labyrinthine segment vascularisation, no branch from the internal auditory artery to the ganglion could be revealed. Only some tiny anastomotic vessels were noticed in
2 foetal specimens between the latter artery twigs and the ganglionic plexus (Fig. 5). On the other hand, certain authors [14] reported that some branches, arising from the internal carotid artery within the carotid canal, occasionally contribute to the supply of the ganglion.

\section{Petrosal artery}

This vessel, which nourishes not only the tympanic segment of the facial nerve but also the geniculate ganglion, was identified in the $19^{\text {th }}$ century by the famous French researcher and clinician Jean Cruveilhier [4]. In spite of this, however, many details about this vessel were not known until recently [12]. Our results are, in general, similar to the data from the latter and some other reports $[5,12,14]$. On the other hand, certain new facts were discovered regarding this artery and its branches in our study.

The parent vessel of the petrosal artery, that is, the MMA, which is a branch of the maxillary artery, was always present and normally developed in our specimens, and it averaged $1.3 \mathrm{~mm}$ in diameter. Only El-Khouly et al. [12] found a very small MMA in one specimen, which ended in the petrosal branch, while Clarke [11] noticed a petrosal vessel to arise from an accessory MMA. Anyway, ligation of the MMA or embolisation of the maxillary artery for epistaxis, or administration of an anticancer drug into the maxillary artery, may compromise the circulation through the petrosal branch, and thus cause the facial nerve palsy $[6,18]$.

A group of the mentioned authors [12] noticed the petrosal artery to arise below the level of the foramen spinosum in 4 cases. We found, however, an intracranial origin of that vessel in all of our specimens. In the mentioned report and in our study, a petrosal, or trigeminal branch, was noticed to supply occasionally both the trigeminal ganglion and the greater petrosal nerve. Damage to such a vessel may lead to a functional disorder of both trigeminal and petrosal nerves [12].

The mean values of the outer diameter and length of the petrosal artery were similar in both studies: $0.44: 0.50 \mathrm{~mm}$, and 17.1:18.0 $\mathrm{mm}$, respectively. The artery approaches the greater petrosal nerve and enters its hiatus, or passes through a bone opening in front and lateral to the geniculate ganglion to reach the tympanic segment of the facial nerve.

The petrosal artery can be damaged when elevating the dura from the floor of the middle cranial fossa during a surgical approach to the trigeminal nerve, 
the Meckel's cave, the cavernous sinus and internal acoustic meatus $[5,10,12]$. Similarly, an iatrogenic injury can also occur while drilling the bone to expose the internal acoustic meatus. In these cases drilling should be performed further to the greater petrosal nerve in order to preserve both the nerve and the petrosal artery. Even compression of the latter vessel may cause a dysfunction of the facial nerve [16].

The petrosal artery gives off side twigs along its course. Only in our study the number and size of the petrosal artery branches were presented. Thus, the twigs to the greater petrosal nerve were found to vary in number between 1 and 3 (mean 1.3), and in diameter from $0.012 \mathrm{~mm}$ to $0.052 \mathrm{~mm}(0.024 \mathrm{~mm})$.

\section{Ganglion vasculature}

Number and diameter of the petrosal artery twigs to the geniculate ganglion were presented almost for the first time in our study. Only Clarke [11] reported them to measure from $60 \mu \mathrm{m}$ to $80 \mu \mathrm{m}$ in diameter. We found the ganglionic twigs to range in number from 1 to 3 , and in size between $18 \mu \mathrm{m}$ and $56 \mu \mathrm{m}$. The twigs usually formed a dense irregular vascular plexus on the surface of the ganglion. Anyway, these tiny branches of the surface network entered the ganglion and formed the intraganglionic vascular plexus.

We found 99.8 microvessels on average in each microscopic field, what is more than in some reports, in which the mean value was 8.5 vessels per field [6]. Some other authors [11], who used a cooper mesh with 200 squares (each measuring 1/200 part of an inch), found 12 vessels per square.

The discrepancy between their and our findings can be explained in several ways. Firstly, the mentioned authors used slices stained with haematoxylin and eosin, while we applied CD34 immunoreactivity, which is a very sensitive method for labelling the endothelial cells of the vessels [1,9]. Secondly, the mentioned authors identified only capillaries, whereas we counted all the microvessels, i.e. both capillaries and precapillaries. Thirdly, those authors excluded the connective tissue, while we counted the microvessels not only around the individual ganglion neurons, but also in the connective tissue surrounding small groups of the neurons (Figs. 8, 9). Since we also counted the number of the ganglion neurons (mean 28.1 per field), we noticed that the average cell/vessel ratio was 1:3.6. In the other words, each neuron is surrounded by 3.6 microvessels.
Obviously, the geniculate ganglion has the richest microvasculature in the facial nerve region $[2,5,11]$. For instance, the mean capillary density is only 1.5-2.0 per field in the labyrinthine segment of the facial nerve, 2.3-4.0 in the tympanic segment, and 3.3-4.8 in the mastoid segment [2, 3]. Accordingly, the labyrinthine and tympanic segments are more vulnerable to ischemic damage, which could be, in association with oedema of the nerve, one of the pathophysiological mechanisms in patients with Bell's palsy [2,3].

Rich blood supply of the geniculate ganglion is a general feature of the groups of the neuronal somata in both the peripheral and central nervous system, because the metabolism rate is much higher in the neuronal bodies than in their processes, and so is their blood supply $[8,20]$. The functional changes in the local blood flow in such regions is the basis for functional magnetic resonance imaging and similar radiological techniques [20]. In addition, some authors suggested that the rich ganglionic vascular plexus could be a predilection site for a haemangioma [2].

Based on our examination and other authors' reports, it is evident that the petrosal artery nourishes both the geniculate ganglion and the tympanic segment of the facial nerve. Therefore, damage or occlusion of the petrosal artery may compromise the blood supply of both the ganglion and the tympanic segment, including the greater petrosal nerve. Consequently, peripheral facial palsy may develop, as well as sensory loss in a part of the auricle and diminished gustatory sensation, lacrimation and secretion of the nasal and palatal glands [17]. There is also the involvement of the ganglion vasculature and neurons in the ganglionitis, caused by a varicella-zoster virus within the ganglion, as well as in patients with geniculate neuralgia $[13,19]$.

\section{CONCLUSIONS}

The geniculate ganglion is supplied by 1 to 3 twigs of the petrosal artery, which form the superficial and deep ganglionic vascular plexus. The microvessels of the plexus surround groups of neurons, but also the individual cells. This study is the basis for further examination of the geniculate ganglion from both the scientific and clinical aspect.

\section{ACKNOWLEDGEMENTS}

This work was supported by grant No. 175061 from the Ministry of Science, Serbia. 


\section{REFERENCES}

1. Balac I, Jurisic V, Laban A, Randelovic T, Knezevic P, Pantic I, Dzodic R (2012) The CD34-microvascular density in colorectal cancer patients. J BUON, 17: 97-101.

2. Balkany T, Fradis M, Javek BW (1991a) Hemangioma of the facial nerve: role of the geniculate capillary plexus. Skull Base Surg, 1: 59-63.

3. Balkany T, Fradis M, Jafek BW, Rucker NC (1991b) Intrinsic vasculature of the labyrinthine segment of the facial nerve - implications for site of lesion in Bell's palsy. Otolaryngol Head Neck Surg, 204: 20-23.

4. Bartholdy K (1897) Die Arterien der Nerven. (in German). Morph Arbeiten, 7: 26-458.

5. Blunt MJ (1954) The blood supply of the facial nerve. J Anat, 88: 520-526.

6. Blunt MJ (1956) The possible role of vascular changes in the aetiology of Bell's palsy. J Laryngol Otol, 70: 701-713.

7. Bosatra A (1956) Some observations on the vascularization of the VIIth nerve. J Laryngol Otol, 70: 605-613.

8. Carpenter MB (1991) Neuroanatomy. 4th Ed. Williams \& Wilkins, Baltimore.

9. Chan K-K, Lowe J (2002) Techniques in neuropathology. In: Theory and practice of histological techniques. 5th Ed. London, Churchill Livingstone, pp. 271-320.

10. Chanda A, Avci E, Fossett D (2002) Middle fossa approach. In: Operative neurosurgical anatomy. New York, Thieme, pp. 61-85.

11. Clarke JA (1965) An X-ray microscopic study of the arterial supply to the facial nerve. J Laryngol Otol, 79: 987-994.
12. El-Khouly H, Fernandez-Miranda J, Rhoton AL (2008) Blood supply of the facial nerve in the middle fossa: the petrosal artery. Neurosurgery, 62 (suppl. 2): ONS297-303.

13. Gilden D (2013) Functional anatomy of the facial nerve revealed by Ramsay Hunt syndrome. Cleve Clin J Med, 80: 78-79.

14. Minatogawa T, Kumoi T, Hosomi H, Kokan T (1980) The blood supply of the facial nerve in the human temporal bone. Auris Nasus Larynx, 7: 7-18.

15. Mom T, Gabrillargues J, Gilain L, Chazal J, Kemena JL, Vanneuville G (2002) Anatomy of the vestibulo-acoustico-facial neurovascular pedicle. Importance of therapeutic management of vestibular schwannomas. (In French). Neurochirurgie, 48: 387-397.

16. Sillman JS, Levine RA, Kobler JB (1994) Laser Doppler measurements of intratemporal facial nerve blood flow. Am J Otol, 15: 327-334.

17. Standring S (2008) Head and neck. In: Anatomy. The anatomical basis of clinical practice. 14th Ed. Churchill Livingstone, Elsevier, London, pp. 395-703.

18. Takeda T, Takeda S, Kozakura K, Saito H (1997) Intratemporal facial nerve blood flow in guinea pigs. Am J Otol, 18: $252-256$.

19. Tubbs RS, Steck DT, Mortazavi MM, Cohen-Gadol AA (2013) The nervus intermedius: a review of its anatomy, function, pathology, and role in neurosurgery. World Neurosurg, 79: 763-767.

20. Van Heertum RL, Tikofsky RS, Ichise M (2010) Functional cerebral SPECT and PET imaging. 4th Ed. Wolters Kluwer, Lippincott, Williams \& Wilkins, Philadelphia. 